\title{
O que aprendi com educação a distância
}

Maria Cristina Castilho Costa

Professora livre-docente do Departamento de Comunicações e Artes

da Escola de Comunicações e Artes da Universidade de São Paulo, editora da Revista Comunicação \& Educação.

E-mail: criscast@jato.com.br

A experiência que venho relatar aos leitores da Revista Comunicação \& Educação teve lugar no Curso de Especialização Lato Sensu Gestão da Comunicação, um curso tradicional na Escola de Comunicações e Artes da USP - já com doze anos e que formou mais de 250 gestores da comunicação. Foi criado por um grupo de professores do Departamento de Comunicações e Artes - o CCA, que se deu conta da necessidade, no mercado, de um profissional coordenador e articulador de diferentes funções e atividades ligadas à Comunicação; um profissional de formação multidisciplinar e visão abrangente, capaz de pensar a comunicação como um processo, o que implica a recusa de uma abordagem funcionalista ou tecnicista. $\mathrm{Na}$ verdade, um profissional com as características desejadas, na atualidade, para as mais diversas funções e áreas: coordenado, articulado, informado, com formação humanista e sem os vícios da especialização redutora ${ }^{1}$.

O curso tem três semestres, sendo dois de formação teórica e o último destinado ao desenvolvimento de um projeto de intervenção para uma instituição de escolha do aluno e que acolha com bons olhos sediar a realização de uma pesquisa em comunicação. Avaliando e buscando aprimorar os processos de comunicação estabelecidos nessa instituição, o aluno elabora o projeto de intervenção sob orientação de um professor credenciado, utilizando para isso recursos e métodos comunicacionais: linguagens, mídias e relações comunicativas. O pressuposto básico desse projeto é de que a comunicação na sociedade se apresenta como o espaço para o diálogo, a troca, a formação da identidade e da cidadania.

A parte de formação teórica - os dois semestres iniciais - é composta por dez núcleos abrangendo estudos da linguagem, comunicação, educação, metodologia de pesquisa, ação administrativa, políticas públicas, expressão estética e estudos dos meios de comunicação. Esse amplo espectro teórico permite aos alunos dedicar-se à proposta de projetos para instituições culturais, educativas, públicas, comerciais, religiosas, assim como para organizações não-governamentais e demais movimentos sociais. Além de coordenadora do curso de Gestão, sou responsável por dois Núcleos: Estética dos Meios de Comunicação e Planejamento $e$ Avaliação de Projetos de Comunicação/Cultura, este último em parceria com o prof. dr. Ismar de Oliveira Soares.

1. BACCEGA, Maria Aparecida (Org.). O gestor e o campo da comunicação. Gestão de Processos Comunicacionais. São Paulo: Atlas, 2002. p. 26. 
A sucessão de Núcleos obedece à divisão por semestre, sendo cinco no primeiro e cinco no segundo. Cada Núcleo é formado por seis dias, de quatro horas, de atividades presenciais, enquanto outras 24 horas são dedicadas às leituras e seminários, além da preparação de trabalhos de conclusão propostos pelos professores/coordenadores. Essas atividades são a distância, pois envolvem gerenciamento, iniciativa e prontidão do aluno, além de pesquisa própria e aplicação dos conceitos trabalhados em aula. No Núcleo de Planejamento, onde se realizou a experiência que venho relatar, o principal objetivo é fazer o aluno encarar, pela primeira vez, a organização para a qual desenvolverá o trabalho de intervenção em termos de uma investigação empírica, com o distanciamento e a objetividade próprios da pesquisa científica. O trabalho final no qual se baseia sua avaliação é a realização do que chamamos de Pré-diagnóstico, um primeiro levantamento da instituição e de seus problemas comunicacionais. Para isso ele segue um roteiro que é estudado em sala de aula, além de fazer leituras que o coloquem em contato com a pesquisa empírica e com a atitude exigida do pesquisador: objetividade, método e curiosidade investigativa.

\section{A EXPERIÊNCIA COM NOVAS MÍDIAS}

Já faz quinze anos que venho me dedicando ao estudo das mídias digitais e da internet na comunicação e na educação formal e informal, institucional e nãoinstitucional, voltadas para diferentes públicos. Meu interesse por essa área teve origem no trabalho que por anos desenvolvi junto ao Instituto Cultural Itaú, onde desempenhei as funções de Superintendente Cultural, gerenciando o banco de dados informatizado sobre pintura brasileira. Nessa época (1989-1994), comecei a estudar a revolução informática e as transformações radicais que ela vinha introduzindo no campo da comunicação. Desde então venho realizando pesquisas que investigam a reação dos internautas na comunicação em rede. Criei e mantenho, na Escola de Comunicações e Artes da USP, desde 1999, um site de Narrativas Interativas, com o qual estudo as estruturas narrativas e a criação ficcional interativa e coletiva. Esse site está acessível no endereço <www.eca.usp.br/narrativas >.

Com esses interesses e tal experiência, julguei importante desenvolver no curso de Gestão da Comunicação atividades a distância. Não para que houvesse redução da carga horária presencial, mas para experimentar as ferramentas digitais e estudar as vantagens e desvantagens das atividades on-line num curso de especialização. Por outro lado, parecia-me que o curso não estaria completo na formação desse profissional versátil e informado ao qual me referi, se ele não estimulasse a discussão e o uso dos novos meios de comunicação. Além disso, pesquisas realizadas no curso mostravam que a grande maioria dos alunos era usuária assídua da internet e havia se interessado pelo curso buscando informações na rede. Considerei também que muitos dos projetos desenvolvidos privilegiavam o entendimento e a aplicação das mídias digitais na prática da comunicação. Havia, portanto, condições básicas para o sucesso da experiência: capacitação, interesse e oportunidade. 


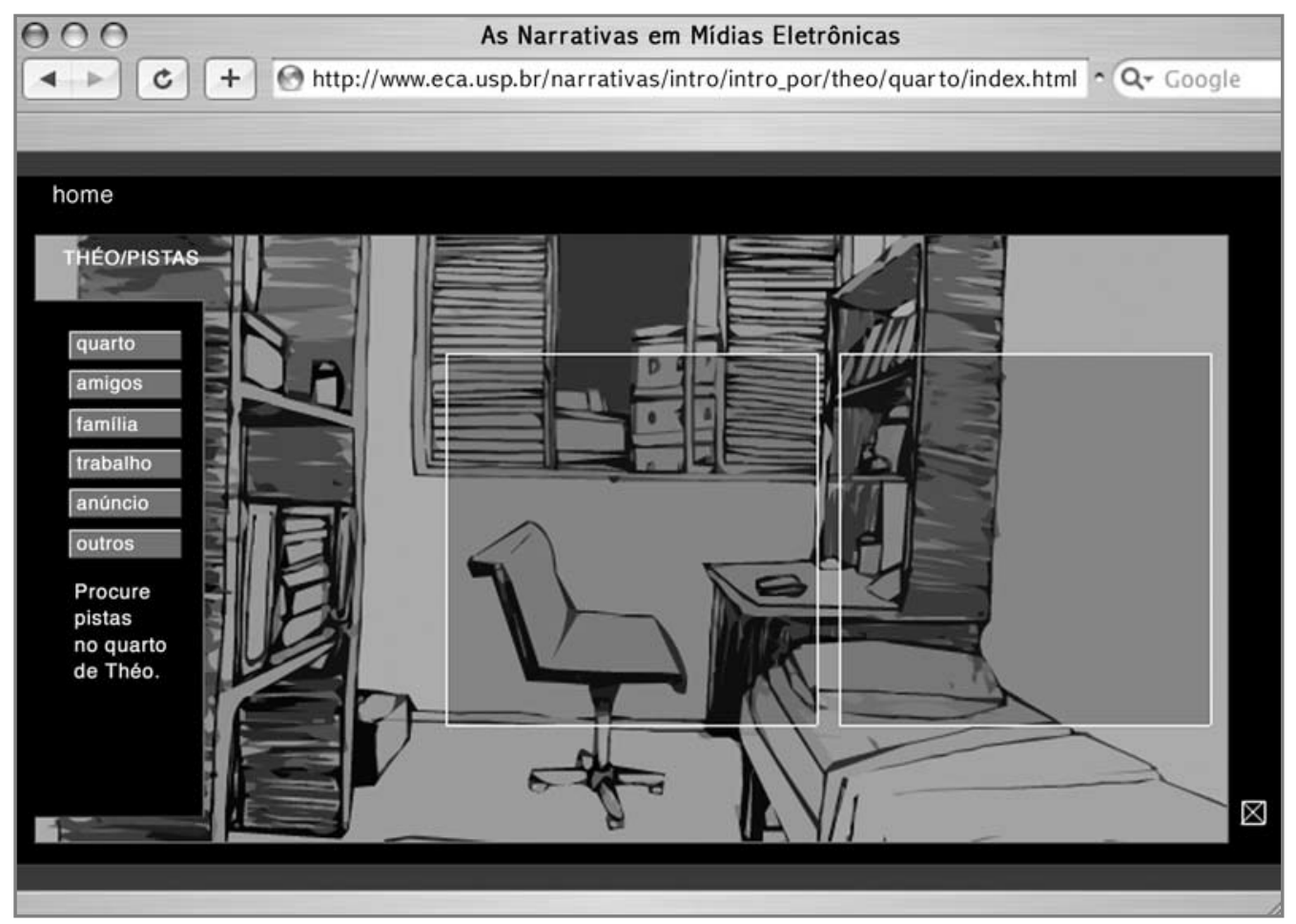

Uma das páginas do site As Narrativas em Mídias Eletrônicas: <http://www.eca.usp.br/narrativas>.

Com base nesses princípios, chamei uma ex-orientanda de mestrado, especialista em meios digitais e internet para trabalhar comigo. Seu nome é Yara Mitsuishi e hoje ela faz doutorado no Canadá em comunicação digital. Criamos, tanto para Estética dos Meios de Comunicação como para Planejamento e Avaliação de Projetos de Comunicação/Cultura, um formulário on-line com temas em aberto para ser preenchido pelos alunos. O primeiro tema deveria ajudá-los na análise de um texto comunicacional, em seus aspectos lingüísticos, técnicos e estéticos, mostrando ter aprendido os conceitos em sala de aula; e o segundo, procurava direcioná-lo para a realização do Pré-Diagnóstico - sobre o qual já falamos.

Aqui já cabe uma observação importante - apesar de a natureza desses dois trabalhos ser bem diferente - o primeiro mais analítico, o segundo mais objetivo e informativo -, a estrutura da atividade on-line foi a mesma e os resultados obtidos bastante semelhantes. Em razão disso podemos dizer que, como em mídias impressas, o formato dos instrumentos de aprendizagem pode ser o mesmo para diferentes conteúdos. Mas, para que os leitores possam entender como funcionaram esses formulários, vou descrever em detalhes apenas um deles, aquele referente à elaboração do Pré-Diagnóstico do Núcleo de Planejamento e Avaliação de Projetos de Comunicação/Cultura.

Nossa primeira preocupação foi estruturar as atividades a distância e dosá-las, criando certo ritmo de trabalho. Dividimos o formulário em quatro partes, a primeira delas dedicada ao estudo da instituição e de sua natureza. A segunda, destinada ao levantamento da comunicação existente na organização. 
A terceira, abordando a relação que o pesquisador mantém com a instituição e, por último, na quarta parte, a identificação do problema comunicacional que deveria ser objeto de intervenção. Estávamos certos de que orientar o olhar do aluno para essas diferentes instâncias, uma de cada vez, já constituiria por si só um importante aprendizado.

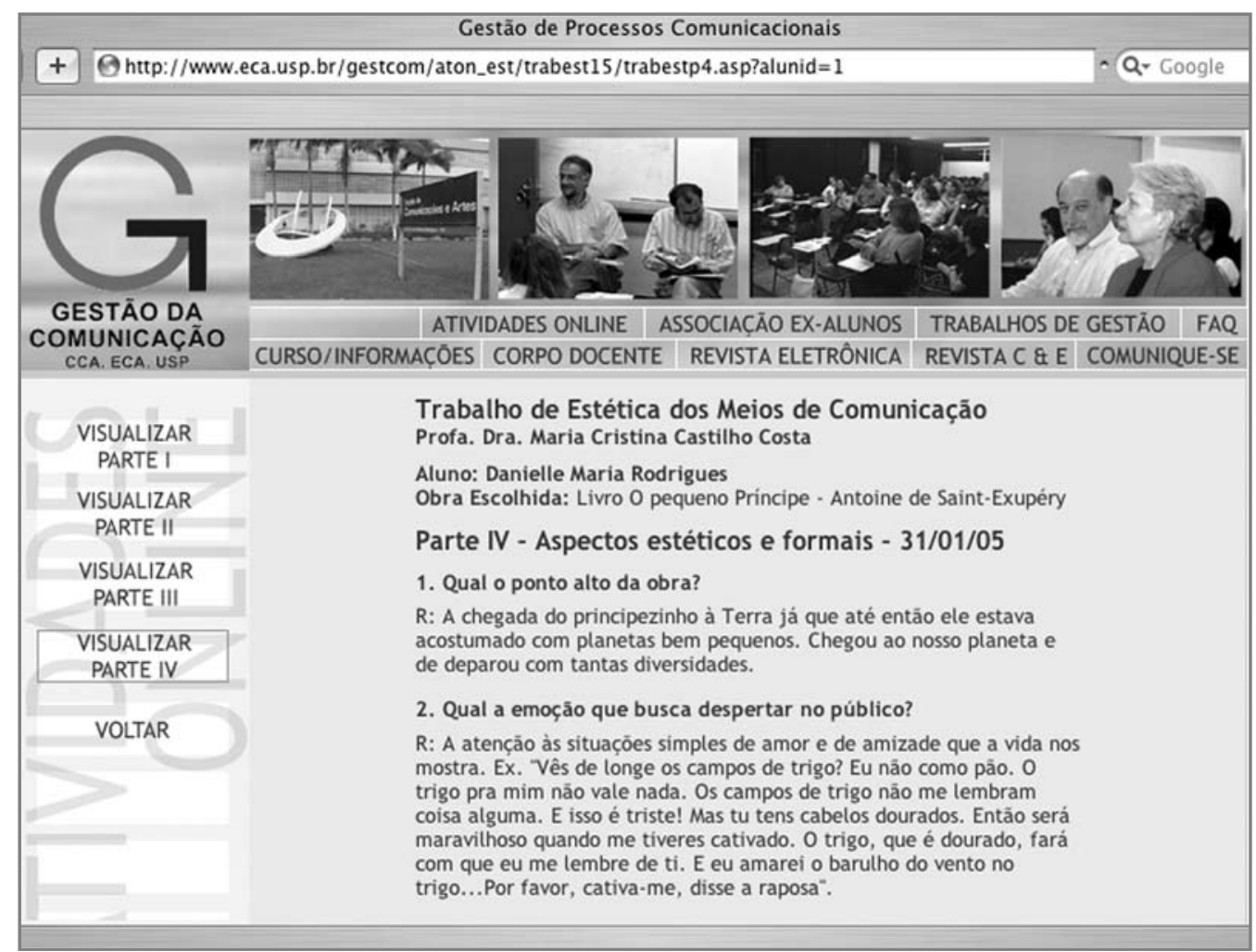

Área de atividades on-line do site do curso de Gestão da Comunicação: <http://www.eca.usp.br/gestcom>.

O formulário contemplava as seguintes informações:

\section{Roteiro - Pré-diagnóstico On-line}

Parte I - Sobre a instituição

Parte II - Sobre a Gestão da Comunicação na organização/instituição

Parte III - Posição e função do pesquisador na organização/instituição

Parte IV - Problema-foco

\section{Parte I - Sobre a instituição}

1. Nome da instituição.

2. Natureza: pública; privada; mista; organização não-governamental; multinacional; transnacional; fundação etc.

3. Atividade: governamental; jurídica; comercial; educacional; industrial etc.

4. Localização: sede e filiais. Indicar o espaço onde se realizará a pesquisa.

5. Dimensões: pequena, média ou grande empresa ou organização. Forneça dados sobre o número de funcionários ou sobre a produção. 
6. Origem: nacionalidade; fundador(es); objetivos iniciais; incentivos; planejamento, primeiros tempos.

7. História: relato de como tem sido o desenvolvimento da organização/ instituição.

8. Linha do tempo: principais eventos que marcaram a história - mudanças de endereço; fusões; compra ou venda de unidades; mudança de gestão; crises econômicas.

9. Entrevista: escolha um dos mais antigos funcionários para relatar a história da organização/instituição.

10. Observação: relato de suas impressões sobre a organização/instituição.

\section{Parte II - Sobre a Gestão da Comunicação da organização/instituição}

1. Responsáveis pela comunicação: Departamento e funcionários cuja função é desenvolver a comunicação.

2. Instrumentos de comunicação: revista; jornal; mural; site; memorandos; comunicação visual e comunicação oral.

3. Comunicação informal: locais de encontro e hábitos dos funcionários para troca de informações.

4. Política de comunicação: principais objetivos a serem atingidos.

\section{Parte III - Posição e função do pesquisador na organização/instituição}

1. Função do pesquisador na organização/instituição: funcionário; ex-funcionário; voluntário; parente; amigo; cliente etc.

2. Trajetória do pesquisador junto à organização/instituição: tipo de relacionamento.

3. Razões da escolha da organização/instituição.

\section{Parte IV - Problema-foco}

1. Problema comunicacional objeto da pesquisa.

2. Indicadores: dados concretos e empíricos do problema.

3. Avaliação microestrutural do problema: aquilo que diz respeito à organização/instituição.

4. Avaliação macroestrutural do problema: aquilo que afeta a organização/ instituição, mas que não diz respeito diretamente a ela, mas à sociedade como um todo.

5. Antecedentes: o que já foi feito na organização/instituição para solução do problema e resultados obtidos.

6. Anexos: o que pode ser adicionado ao relato para maior compreensão do problema-foco.

\section{METODOLOGIA DE TRABALHO}

Para tornar viável o trabalho, o formulário foi publicado em uma área restrita do site do curso, que funciona no endereço <www.eca.usp.br/gestcom>. No primeiro dia de aula do Núcleo de Planejamento, os alunos receberam, 
por e-mail, os dados que lhes davam acesso a essa área restrita. Poderiam assim navegar à vontade para entender o que se esperava deles e avaliar suas dificuldades. As duas primeiras semanas foram dedicadas à solução de todas as dúvidas, além das leituras correspondentes que, como já expliquei, têm por finalidade ensinar o aluno a desenvolver uma postura de pesquisador. Da terceira semana em diante, os alunos começavam a preencher o formulário e a publicá-lo. Um aviso no site comunicava que a parte do formulário estava disponível para avaliação. Entretanto, somente eu tinha acesso aos trabalhos, podendo lê-los e comentá-los, utilizando para isso uma área reservada ao final de cada parte. Assim, antes de passar à seção seguinte, o aluno podia corrigir seu trabalho ou aperfeiçoá-lo até a publicação final, quando o Pré-diagnóstico era considerado terminado. Meus comentários também só eram acessíveis a ele, estabelecendo-se uma relação direta entre professor/aluno.

Cada parte era preenchida numa semana, o que imprimiu um ritmo interessante ao trabalho. Necessitando comunicar-se com o professor para resolver suas dúvidas, o aluno recorria ao e-mail, embora em muitas experiências de ensino a distância uma área de trabalho seja reservada para isso. Ao final, depois de todas as correções, o Pré-diagnóstico era tornado público, podendo ser acessado na área de Atividades on-line, do site do curso de Gestão da Comunicação.

Esse trabalho foi realizado com sucesso com as últimas duas turmas formadas pelo curso de Gestão da Comunicação, e é com base nessa experiência que passo a relatar as vantagens e as desvantagens que consegui perceber nessa experiência.

\section{VANTAGENS OBSERVADAS}

1. A primeira vantagem observada foi a motivação do grupo. Os alunos acharam muito interessante trabalhar na internet e passar por essa experiência diferente de se manter em contato com o professor fora do tempo em que fica em aula.

2. As atividades on-line, quando planejadas e estruturadas, são autoexplicativas e vão ensinando o aluno à medida que ele realiza seu trabalho. Sendo divididas em etapas, as chances de não-aprendizagem se tornam decrescentes. Ele realmente vai aprendendo enquanto trabalha, reafirmando seu conhecimento nos encontros presenciais que se intercalam.

3. A atividade on-line aproxima o professor do aluno, pois a relação se torna individualizada, ao contrário do que acontece em sala de aula, em que apenas os alunos mais extrovertidos ou familiarizados com um conteúdo se expressam. Nas atividades a distância, cada um deles está em contato direto com o professor, tendo a certeza absoluta de que este o lê (escuta). Essa aproximação faz com que ele se torne mais exigente e aguarde os comentários com ansiedade. 
4. Por saber que, ao final, seu trabalho será publicado no site, o aluno procura aperfeiçoá-lo, o que transforma a presença da mídia num reforço pedagógico. Assim, embora individualizado em seu processo, o trabalho de educação a distância tende a se tornar coletivo e público, na medida em que a internet vem se transformando um uma imensa e planetária enciclopédia.

5. O fato de o aluno poder ir corrigindo seu trabalho de acordo com as expectativas do professor, torna o exercício um verdadeiro processo de aprendizagem, do qual a avaliação é apenas uma das etapas. Ela deixa de constituir um recurso disciplinar na relação professor/aluno ou um fator de surpresa e desapontamento do aluno em relação a seu desempenho.

6. Além de aprender um conteúdo, nos trabalhos on-line o aluno adquire conhecimento também do uso de uma nova linguagem. Em grupo e sob orientação do professor, muitos deles perdem seus receios e suas prevenções em relação ao computador.

7. Os trabalhos on-line permitem gerenciamento do tempo, pois é uma mídia que está 24 horas à disposição dos usuários. As experiências com educação a distância mostram uma concentração de trabalho em finais de semana e à noite, quando se tornaria difícil a locomoção do aluno para uma biblioteca ou para outro espaço de pesquisa.

8. Apesar da inibição em escrever - muitos usuários da internet temem cometer erros de gramática e ortografia -, uma vez iniciado o processo de trabalho, a própria mídia estimula o usuário a continuar. E há muitas ferramentas para corrigir e dar acabamento à tarefa, o que não acomoda o aluno, antes, o estimula.

9. A atividade inovadora, por si só, é um estímulo e tira o aluno dos vícios da sala de aula: desatenção e desinteresse diante de situações que ele pensa conhecer ou já ter visto e sobre as quais pensa ter certo controle.

\section{DESVANTAGENS OBSERVADAS}

1. Problemas técnicos ocorrem continuamente e é preciso que se tenha um webmaster responsável à disposição para eventuais (mas assíduas) falhas, tais como senhas que não funcionam ou trabalhos que não conseguem ser enviados. Um técnico para corrigir avarias nos equipamentos também deve estar disponível.

2. O trabalho do professor é mais intenso, pois ele se compromete com uma relação sincrônica que se estende para além do horário de aulas. Assim, para obter melhores resultados sem sobrecarregar o professor, é conveniente que ele disponha sempre de um monitor que o ajude na leitura das atividades e nas respostas às dúvidas dos alunos. Um monitor por grupo de quinze a vinte educandos é o ideal. Há alunos com grande 
destreza na operacionalização de computadores, que se prestam a esse tipo de auxílio e há escolas que dispõem de monitores de informática para ajudar o professor nessas iniciativas.

3. Há dificuldade na leitura de trabalhos on-line, pois a tela vertical e plana, iluminada por luz emitida e não refletida, não é o meio ideal para leitura. Caso o professor tenha essa dificuldade ou o trabalho seja longo, convém ter à mão uma cópia impressa do trabalho realizado.

4. Nem todos os alunos dispõem de equipamentos com bons recursos, nem de conexão com a internet. Poucos têm, em casa, banda larga ou internet rápida, ferramentas que facilitam o trabalho em redes de computadores. Essas diferenças devem ser consideradas no planejamento da educação a distância. Esperamos que políticas públicas coloquem à disposição dos alunos e das instituições de ensino equipamentos condizentes. Não é possível pensar na educação a distância como um privilégio.

5. Por se tratar de uma metodologia nova, há substanciais diferenças individuais quanto à facilidade no uso da tecnologia e capacidade de expressão. Os trabalhos apresentam mais diferenças no grau de resolução do que no uso de linguagens convencionais. Nesse sentido, o trabalho de explicação dos objetivos e das expectativas do professor se torna estratégico.

6. Por se constituir a educação a distância um trabalho individualizado que envolve múltiplas aprendizagens de conteúdo e forma, o número de alunos a serem bem atendidos por um professor ou monitor não é grande, dado o tempo que esse atendimento consome. Assim, para atingir um grupo maior de educandos, é preciso contar, igualmente, com uma extensa equipe de trabalho formada de monitores e auxiliares. A razão um para quinze e um para vinte não pode ser facilmente alterada num trabalho como o aqui descrito.

\section{NEM VANTAGENS NEM DESVANTAGENS}

Há peculiaridades no uso das mídias digitais que não consegui identificar como vantagens nem como desvantagens, mas que não podem deixar de ser consideradas. São elas:

1. Trabalhar com novas tecnologias e educação a distância implica planejamento tático e estratégico, pois, como vimos, trata-se do uso de novas linguagens e diferente relacionamento entre professor e aluno. Assim, impossível improvisar. Nesse processo de planejamento e gerenciamento de ações, o professor se transforma nesse gestor da comunicação que brevemente descrevemos no início deste texto. Considero isso uma vantagem, do ponto de vista do ganho para o professor, para o aluno e para o processo de aprendizagem, mas acho também uma desvantagem para toda a conjuntura educacional que enfrenta certo tipo de precariedade - muitos alunos e poucos recursos. 
2. Os bons resultados das atividades de educação a distância dependem, muitas vezes, de sério trabalho presencial - estabelecimento de relações de contato e compromisso com o trabalho, tradição da instituição que realiza a experiência e alto grau de motivação de professor e alunos em torno dos objetivos a serem alcançados. Infelizmente, tudo isso depende de um forte e contínuo trabalho aqui, agora e sempre.

3. Sendo a educação a distância um trabalho de ensino/aprendizagem que exige forte motivação do aluno e capacitação do professor, além de certo grau de disciplina de ambos, os bons resultados estão atrelados à maturidade dos envolvidos - alunos, técnicos, monitores e professores. Assim, os resultados serão tão melhores quanto mais alto for o grau de formação em que se insere o curso.

4. Como conseqüência de tudo que foi dito acima, assim como em relação ao perfil dos profissionais de comunicação em torno dos quais se organizou o curso de Gestão da Comunicação, os bons resultados do uso da educação a distância dependem da capacitação dos professores para um outro tipo de postura e relação com seus educandos - mais aberta, flexível e personalizada, capaz de encarar o novo como desafio e não como ameaça.

\section{CONSIDERAÇÕES FINAIS}

É importante pensar que nenhuma das vantagens apontadas acima é exclusiva dos trabalhos on-line. É possível propormos, por exemplo, atividades dosadas e estruturadas em temas para que os alunos as desenvolvam sob orientação do professor, podendo corrigir seus erros e aprendendo com eles. É possível também encarar trabalhos presencias de forma mais individualizada que leve em consideração as facilidades e dificuldades de cada um diante do uso de linguagens. Mas acontece que cada meio acaba por gerar uma cultura que lhe é própria, com expectativas que orientam a conduta dos participantes. Assim, é mais difícil inovar na sala de aula, em trabalhos rotineiros, em processos de aprendizagem convencionais, nos quais cada ator já sabe o que o espera e cria expectativas em relação ao seu desempenho e ao desempenho do outro.

Manuel Castells, um dos mais importantes estudiosos da comunicação em rede, aborda esse aspecto quando, parafraseando Neil Postman, diz "Nossas linguagens são nossas mídias. Nossas mídias são nossas metáforas. Nossa metáforas criam o conteúdo de nossa cultura"2. É Castells quem aponta para o fato de que somos atraídos para o caminho de menor resistência. Assim, se trabalhar com meios de comunicação em sala de aula já imprime novas diretrizes ao trabalho do educador, trabalhar com comunicação em rede exige vontade, disposição e criatividade.

Muitas resistências aos métodos de educação a distância surgem quando se compara a educação presencial com aprendizagem mediada por rede de computadores, considerando-se esta última como mais impessoal e desumana.

2. POSTMAN, Neil. Amusing ourselves to death: public discurse in the Age of Shuw Business. In: CASTELLS, Manuel. A comunicação em rede. São Paulo: Paz e Terra, 1999. p. 354. 
No entanto, o que estamos propondo é o uso combinado das duas, lembrando que a educação a distância oferece recursos e ferramentas para experiências diferentes e novas formas de cognição. Não se trata, portanto, de substituir uma metodologia por outra, mas de combiná-las, extraindo os maiores benefícios de ambas.

Mas, se para alunos que têm acesso a aulas presenciais, e dispõem de recursos financeiros e disponibilidade de tempo, são visíveis os benefícios do uso combinado de métodos de ensino presencial e a distância, o que se dirá daqueles que estão distantes e não dispõem de tempo nem de recursos para se dirigir aos centros de aprendizagem? É nesses termos que precisamos pensar tais alternativas - como possibilidades flexíveis que devem ser analisadas, experimentadas e geridas de acordo com as necessidades de cada educando e de suas carências, assim como do preparo e disposição de cada educador.

As experiências nos permitem rever condutas, pensá-las de forma crítica e fazer da educação uma permanente construção de caminhos e meios de comunicação.

Resumo: A autora relata a experiência que teve com a educação a distância no Curso de Especialização Lato Sensu Gestão da Comunicação da ECA-USP. No relato são apresentadas as peculiaridades, vantagens e desvantagens do trabalho on-line combinado com a educação presencial. Nesta seção o leitor encontrará uma visão crítica sobre o assunto e uma valiosa contribuição para a construção de caminhos alternativos na educação.

Palavras-chave: educação a distância, atividades on-line, mídias digitais, internet, Gestão da Comunicação.
Abstract: The author narrates her experience with distance education in the specialization course Communication Management in ECA-USP. She presents the peculiarities, advantages and disadvantages of the online work combined with presential teaching. In this section, the reader will find a critical vision on that issue and a valuable contribution for building alternative paths for Education.

Keywords: distance education, online activities, digital media, internet, Communication Management. 